\title{
¿Globalización de la cultura jurídica en Roma?: Municipalidad y Autonomías*
}

\author{
Teresa Giménez-Candela \\ Catedrática de Derecho Romano \\ Universitat Autònoma de Barcelona
}

\begin{abstract}
El título de este trabajo no pretende ser una provocación. Quiere ser solamente una forma de abordar un problema asíduamente tratado, muy de actualidad y aún no resuelto. Me refiero al de la relación en Roma entre ordenamiento jurídico central y derechos locales ${ }^{1}$; es decir, a la coexistencia entre una cultura jurídica oficial - a la que se atribuye un valor universal- y el respeto a la autonomía local de los territorios integrados bajo el dominio de Roma. El propósito de estas reflexiones es tratar de iluminar, con la ayuda de la reflexión histórica, las últimas tendencias en materia de ordenación municipal que se perfilan en estos años en España.
\end{abstract}

Hoy en día globalización o mundialización son términos que describen un complejo fenómeno de interdependencia económica y social, que ha generado «el intercambio de bienes y servicios y la circulación de capitales — resumido por razones de comodidad en la expresión 'mundialización de la economía'que requiere una acción global y universal» ${ }^{2}$ de las organizaciones supranacionales, independientemente de los criterios de soberanía de los Estados

\footnotetext{
* Una versión en francés, fue objeto de una comunicación en las Journées de la Société d'Histoire du Droit, celebradas en Valladolid, del 8 al 11de Junio de 2006. Agradezco a mis amigos y colegas Catalina Escuín Palop, Vicente Escuín Palop (Universidad de Valencia) y Joan Amenós (Universitat Autònoma de Barcelona), Profesores de Derecho Administrativo, las sugerencias y críticas formuladas tras la lectura del manuscrito.

${ }^{1}$ Una visión de conjunto sobre el debatido problema de la subsistencia de los derechos locales frente a una pretendida unidad jurídica del Imperio, ofrece VOLTERRA, «I diritti locali», en I diritti locali nelle province romane con particolare riguardo alle condizione giuridiche del suolo, Roma 26-28 Ottobre 1971 (Roma 1974) pp. 55 ss., esp. p. 64. (=Scritti Giuridici V [Napoli 1993] p. 399 ss.); NöRR, «Imperium und polis in der höhen Prinzipatszeit», ahora en Historiae Iuris Antiqui I (2003) pp. 391 ss., reproduce el texto - sin notas- de una comunicación del autor al 15. Deutschen Rechtshistorikertag, celebrado en Viena en octubre de 1964; CRAWFORD, «The Laws of the Romans: Knowledge and difusión», en Estudios sobre la «Tabula Siarensis», González y Arce (ed.), (Madrid 1988) pp. 127 ss., posteriormente ampliado en Roman Statutes I (London 1996) 'General introduction' pp. 1 ss.; GabBA, L'imperialismo romano, Storia di Roma II.1 (Torino 1990) pp. 189 ss; Spagnuolo Vigorita, Cità e Impero (Napoli 1996); AMELOTTI, «Reichsrecht, Volksrecht, Provinzialrecht. Vecchi problemi e nuovi documenti», en SDHI 65 (1999) pp. 211 ss.; MigLiaRd ZINGALE, «Diritto Romano e diritti locali nei documenti del vicino Oriente», en SDHI 65 (1999) p. 217 ss.; Merola, Autonomia locale-governo imperiale. Fiscalità e amministrazione nelle province asiane (Bari 2001); KLINGENBERG, «Autonomia locale e governo imperiale», en Index (30) 2002 pp. 337 ss.
}

${ }^{2}$ OIT, La actividad normativa de la OIT en la era de la mundialización. «85. Conferencia Internacional del Trabajo« (Ginebra 1997) 4 ss. 
particulares. Este fenómeno, favorecido por la actual bonanza económica mundial, se predica como fruto irreversible de las nuevas tecnologías en el campo de las comunicaciones, que han homogeneizado el lenguaje y el acceso a las fuentes de conocimiento, relegando las peculiaridades nacionales a un rincón obsoleto, destinado a desaparecer o a rebrotar con virulencia. Asistimos hoy, con una mezcla de euforia y temor (también en el ámbito judicial) a la desaparición de las barreras estatales y de las jerarquías locales - que desde las ideologías del humanismo renacentista se habían construido trabajosamente-, haciendo «más atractiva la tentación de no intervenir cuando no la de desreglamentar» ${ }^{3}$ (como ya se decía en una normativa de la OIT del año 97).

1. El siete de Agosto del 2000 la prensa española ${ }^{4}$, ya se hizo eco de la noticia de que el Ministerio de Administraciones Públicas (MAP), tenía en preparación una propuesta de transferencia de algunas competencias autonómicas a los municipios, que debería alumbrarse con el nombre de «Pacto Local» en el otoño ${ }^{5}$. Tal propuesta tenía como pretensión reforzar las atribuciones de los Ayuntamientos en distintos campos, dando especial relieve a las actuaciones sociales y urbanísticas. Para entender la trascendencia de una iniciativa semejante, conviene tener presente que la descentralización ha sido uno de los esfuerzos prioritarios de la España democrática y uno de los pilares en que se ha asentado la nueva organización político-administrativa, en la que los poderes autonómicos se han visto paulatina y crecientemente reforzados ${ }^{6}$. Ello ha generado, lo que - con una cierta dosis de ironía- se ha dado en llamar «centralismo autonómico», un problema de difícil justificación sobre todo en determinadas materias, si se piensa que la eficacia de la Administración parece garantizada, tanto más cuanto más cerca están los centros de decisión del ciudadano ${ }^{7}$.

En efecto, la reforma propiciada por el Ejecutivo trataba de acortar aún más las distancias entre los centros de decisión y los destinatarios de las mismas. Es claro que el llamado Estado de las Autonomías, denominación que califica en España un régimen basado en la atribución a las comunidades autónomas de competencias de distinta proyección y amplitud, que van

\footnotetext{
${ }^{3}$ OIT, ibidem, pp. $5 \mathrm{~s}$.

${ }^{4}$ El Mundo, 7.8.2000, pp. 1, 3 y 7.

${ }^{5} B O E$, n. $^{\circ}$ 96, de 22 de abril de 1999; BOE, n. ${ }^{\text { }}$ 128, Ley 3/2003 de 11 de marzo para el desarrollo del Pacto Local.

${ }^{6}$ CE. Arts. 137,140 y 141

7 Cfr. por todos, Escuin PAlop, V., «Notas sobre la autonomía y descentralización a favor de los entes locales», en Nuevas perspectivas del Régimen Local. Estudios en Homenaje al profesor Boquera Oliver (Valencia 2003), pp. 757-778; Alonso MAS, M. J., «Comentarios a la Ley Básica de Régimen Local (Ley 7/1985, de 2 de abril, Reguladoras de las Bases de Régimen Local)», volumen coordinado por Domingo Zaballos, M. J. (Madrid 2003) pp. 101-164; SoSA WAGNER, Manual de Derecho Local (9a ed. Pamplona 2005).
} 
desde la Educación o la Sanidad, a la gestión del suelo o del Tráfico ${ }^{8}$, ha tenido como efecto que el ciudadano haya visto aproximarse cada vez más los centros de decisión ${ }^{9}$. Cierto es que los habitantes de pequeñas capitales de provincia, así como de pueblos, ya no dependen exclusivamente de un poder centralizado, con sede en la capital del Estado, pero el hecho claro es que a pesar de tal acercamiento el poder aún resulta distante. El Pacto Local pretendía poner de acuerdo a comunidades y Ayuntamientos con el fín de que algunas competencias de las primeras pasasen a los segundos.

El proyecto gubernativo contemplaba una realidad que había ido paulatínamente afirmándose, a saber, que en muchos municipios - sobre todo en aquellos de tamaño, pudieramos decir, medio- los ayuntamientos exceden de hecho las competencias que la ley les atribuye y prestan muchos otros servicios, destacadamente aquellos que conforman lo que se suelen denominar Servicios Sociales ${ }^{10}$. De ahí, que la idea de transferir a los municipios, desde las comunidades autónomas, nuevas y ampliadas competencias suponía, de entrada, una iniciativa gubernativa que encontró una inmediata acogida en el ámbito local. La perspectiva de reforzar las prerrogativas urbanísticas y sociales de los Ayuntamientos, no estaba carente de riesgos, como bien ha demostrado la experiencia reciente ${ }^{11}$. Quizá la reserva de la potestad fiscalizadora final a cargo de las comunidades, podría ser una medida armonizadora y de interés para salir al paso de posibles tentaciones de corrupción.

El proceso que se anunciaba debía ir acompañado de la paralela transferencia de las partidas presupuestarias, tal como aparece reflejado en la definición de intenciones del Pacto Local, que ha ido trascendiendo al conocimiento público ${ }^{12}$. La financiación local va a tropezar con la dificultad de la supresión del Impuesto de Actividades Económicas (IAE) ${ }^{13}$, que es el segundo en importancia tras el Impuesto de Bienes Inmuebles (IBI). En efecto, la eliminación de tal impuesto constituyó una promesa electoral del actual Ejecutivo, que, de ser cumplida, supondrá un importante deficit para la financiación local. Conviene tener presente que el $90 \%$ de las empresas tributa en los municipios por este concepto y que, si se quiere mantener intacta la capacidad financiera de los 8.107 municipios existentes en España, habrá que

\footnotetext{
${ }^{8}$ Cfr. Ortega Alvarez, «El régimen local y estatutos de autonomía», REALA (=Revista de Estudios de la Administración Local y Autonómica) 300-301 (2006) pp. 35 ss.

${ }^{9}$ Vid., Sosa WAGNer, Derecho Local, cit. pp. 60 ss.

${ }^{10}$ Un ejemplo singular de este tipo de competencias, lo constituye el Ayuntamiento de Madrid, cuyos programas y campañas de lucha contra la droga, exceden quizá lo que por ley le correspondería.

${ }^{11}$ Me refiero singularmente al caso del Ayuntamiento de Marbella en tema de recalificación de terrenos.

${ }^{12}$ Bellod Redondo, «El ajuste presupuestario en las entidades locales», REALA 298-299 (2005) pp. 357 ss.

${ }^{13}$ Arts. 80.1; 83; 89, Ley 39/1988, Reguladora de las Haciendas Locales. Vid. SoSA WAGNER, Derecho Local, cit. pp. 245 ss.
} 
suplir el deficit que supondría la eliminación del IAE con la creación de nuevos impuestos, entre los que se anuncian los relacionados con el medio ambiente o las telecomunicaciones. En este sentido, y en el ámbito autonómico, puede tomarse en consideración la iniciativa de la Comunidad Balear de imponer en verano a los turistas una Ecotasa, iniciativa que fue muy ampliamente contestada y generó una interesante polémica entre dicha comunidad y los principales Tour Operadores, que encauzan el turismo del norte y centro de Europa hacia la Isla. Los municipios vienen suministrando desde hace ya algún tiempo la mayor parte de los servicios relacionados con el medio ambiente, como es el caso de la depuración de las aguas o el reciclaje y ello, hasta el momento, sin recursos financieros específicos, lo que vuelve a poner de actualidad una vieja idea de los estudiosos de las realidades municipales de la creación de figuras tributarias nuevas o de reforzamiento de las ya existentes.

Otro aspecto del Pacto Local es la pretensión del Ministerio de Administraciones Públicas de reforzar las competencias de los alcaldes frente al Pleno ${ }^{14}$, con el fín último de facilitar la gobernabilidad en aquellos ayuntamientos donde el Alcalde carece de mayoría absoluta. Es sabido que la relevancia tanto administrativa como sociológica de los municipios, coloca a estos en el primer orden de importancia dentro de los entes locales, frente a la provincia o la isla, que gozan asimismo de personalidad jurídica. También tiene un carácter preceptivo la comarca, si lo prevé el Estatuto de Autonomía de la Comunidad Autónoma, como es el caso de la Comunidad Autónoma de Cataluña ${ }^{15}$. La tendencia del Proyecto parece ser hacer algo más presidencialistas los municipios y, en tal sentido reactivar también el Pacto Antitransfuguismo. Es un dato constatado que, los votos de los concejales tránsfugas han sido decisivos en 13 de las 37 mociones de censura que han triunfado en España desde las últimas elecciones municipales, de Junio de 1999 lo que supone que el $0,13 \%$ de las Alcaldías ha cambiado de manos desde Junio de 1999 por causa de esta práctica reprobable. Si bien se trata de una cifra porcentualmente poco significativa, sí lo es esta lacra que puede en los años venideros adquirir mayores proporciones, con el consiguiente descalabro de la gobernabilidad municipal.

Dada la estructura de un Estado de las Autonomías como España, estas reformas en pro de un mayor protagonismo de los municipios, vienen a plasmar una idea ya bastante difundida entre los expertos y una tendencia coherente con las nuevos cambios sociales, como es la de reestructurar la vida municipal para acercarla a los ciudadanos. Interesante es — como anécdota-, el que cada vez se habla más de los «ciudadanos» y menos de los «administrados». Este retorno a la búsqueda de las raíces comunes de la ciudadanía no está exenta de intereses económicos, pues las competencias de los muni-

\footnotetext{
${ }^{14}$ Arias Martínez, M. a A.-FerReira Fernández, A. J., «El Pacto Local y la reorganización competencial de la estructura interna de las Corporaciones locales», en REALA 282 (2000) pp. 159 ss.

${ }^{15}$ Sosa WAGner, Derecho Local, cit. pp. 131 ss.
} 
cipios les permiten — con el alcance que determine la Ley de cada sectoraprobar normas reglamentarias (denominadas Ordenanzas locales), dictar resoluciones $\mathbf{o}$ actos administrativos y ejercer actividades de mera gestión ${ }^{16}$.

2. Es claro que no pretende hacerse un parangón exacto entre la actual situación y la relativa al mundo romano. Las categorías conceptuales que empleamos hoy, no encuentran una exacta equivalencia con el término histórico correspondiente, como es ya el caso del mismo término autonomía ${ }^{17}$. Sin embargo, y al margen de los paralelismos que en todo proceso histórico puedan advertirse, no deja de ser atractiva la idea de cuestionarse, hasta qué punto puede subsistir, después de los últimos descubrimientos epigráficos ${ }^{18}$, la idea de un mundo homogéneo y unificado bajo la égida romana en el que las diversidades locales, encontraron una armonización que superó fronteras culturales tan vagas como firmes, como las existentes (por mencionar sólo un ejemplo) entre los territorios de Oriente y Occidente. La cuestión aún abierta es si, a través de las fuentes que tenemos a nuestra disposición - jurídicas y literarias-, y especialmente a través de las fuentes epigráficas y papirológicas, que nos informan acerca de la práctica del derecho, puede fundamentarse la afirmación de la homogeneidad de la cultura jurídica romana ${ }^{19}$.

Es, desde luego, una cuestión actual aunque no nueva; pues éste y no otro es el problema, que propulsó la especulación científica de finales del siglo pasado e inicios del presente, dominada por la visión moderna del Estado nacional, en el que el principio de la igualdad jurídica de los individuos, debería fundarse en la vigencia en cada ámbito estatal de un único derecho privado $^{20}$. Una obra tan significativa como «Reichsrecht und Volksrecht $»^{21}$ (cuya traducción podría ser «Derecho oficial y derecho propio de las pobla-

\footnotetext{
16 Art. 4.1 de la Ley 7/1985 de 2 de abril reguladora de las Bases del Régimen Local.

17 Cfr. NöRR, Imperium und polis (cit.) p. 6, n. 26, quien, en contra de Mordzejewski, SZ 80 (1963) p. 53, sostiene que autonomía no significa administración independiente, sino independencia interna $(\alpha \cup \tau o v o \mu i \alpha)$, aunque a veces aparezca en un sentido próximo a libertas $(\varepsilon \lambda \varepsilon \cup \vartheta \varepsilon \rho i \alpha)$ con el significado de independencia respecto del exterior, tal como aparece en Cicerón y en Arístides (Cic. ad Att. 6,2,4; A. Aristides, $\varepsilon\llcorner\sigma$ Pounv 224 [392] cap. 96).

${ }^{18}$ En relacion a la ley Irnitana, vid. por todos LAMBERTI, «Tabulae Irnitanae». Municipalità e Ius Romanorum (Napoli 1993).

19 StYlow, Los inicios de la epigrafía latina en la Bética. El ejemplo de la epigrafía funeraria, Roma y las primeras culturas epigráficas del Occidente mediterráneo (Zaragoza 1992), sobre la aparición en época augústea de talleres epigráficos.

${ }^{20}$ Volterra, Diritti locali (cit.) p. 56; CAPOGRo SSI COLOGNESI, «Le forme gromatiche del territorio e I vari regimi giuridici dell'ager romanus e dell'ager colonicus. Il complesso mosaico della romanizzazione italica», en Gli Statuti municipali, ed. Capogrossi Colognesi-Gabba (Pavia 2006) pp. 594 s.

${ }^{21}$ MITTEIS, Reichsrecht und Volksrecht in den östlichen Provinzen des römischen Kaiserreiches (Leipzig 1891). Posteriormente, MITTEIS-WILCKEN, Grundzüge und Chrestomathie der Papyruskunde, II Juristischer Teil (Berlin 1912).
} 
ciones de cultura helenística»), dio a Mitteis la ocasión de poner de relieve, la tenaz resistencia de las costumbres helenísticas locales a la asimilación con el derecho imperial. La obra de Mitteis tuvo un reflejo inmediato en los trabajos de grandes estudiosos de épocas sucesivas, bien en apoyo de su hipótesis, bien en contra de la misma ${ }^{22}$.

La polémica se centró, a partir de la década de los años 30 en torno a los efectos y el significado de la Constitutio Antoniniana que, en el 212 d.C., extendió la ciudadanía a todos los súbditos libres del Imperio (una medida globalizadora, como diríamos hoy), lo que supuso —-según se sostiene-, no sólo una nivelación de los derechos de participación ciudadana de todos los habitantes del Imperio, sino también de las tradiciones jurídicas locales ${ }^{23}$.

El estudio del Pap. Giessen 40,I, fuente principal de conocimiento de esta importante disposición -irremediablemente dañado tras la II Guerra Mundial-, no ha permitido avanzar excesivamente en la naturaleza de este hito relevante del gobierno de Antonino Caracalla. Alvaro d ${ }^{\circ}$ Ors, cuya tesis doctoral versó precisamente sobre el Papiro Giessen ${ }^{24}$, fundamentó en él su afirmación de que la concepción política de Roma fue más personal que territorial, superando de este modo la concepción política griega uncida a la demarcación territorial de la $\pi \circ \lambda \iota \sigma^{25}$, cuyos límites geográficos impidieron una mayor expansión del dominio griego en el Mediterráneo, frente a la ciudadanía (civitas), evidenciada en el nomen romanum, que convertía, a quien podía aducir el triple nombre (tria nomina), en un ciudadano sin fronteras geográficas. La civitas sería la comunidad del nomen ${ }^{26}$, más que el territorio o la forma en que ésta se proyecta historicamente: oppidum, vicus, pagus, colonia, municipium $^{27}$.

Lo que la Constitutio Antoniniana habría evidenciado, en contraste con la uniformidad que pretendía lograr, fue la persistencia de una praxis local pre-

\footnotetext{
${ }^{22}$ Cfr. Volterra, Diritti locali (cit.) pp. 60 s.; Amelotti-Migliardi Zingale, vid. supra $n .1$ (=Atti del Congreso Internazionale della Società Italiana di Storia del Diritto, Torino 19-21 Novembre 1998 [Roma 2001] pp. 277 ss.)

${ }^{23}$ BURASELIS, «Peithesai Romaiois: considerations on the oficial relation of Rome to the provinces before and after the Constitutio Antoniniana», en Identità e valori: fattori di aggregazione e fattori di crisi nell'esperienza politica antica, Bergamo 16-18 Decembre 1998 (Roma 2001) pp. 183 ss.; Gallo, «Le consuetudini locali prima e dopo la concessione della civitas romana ai peregrini», en Diritto generale e diritti particolari (cit.) pp. 303 ss.; BANCALARI MOLINA, «Coexistencia o enfrentamiento entre el Derecho Romano y los derechos locales de las provincias», en REHJ 26 (2004) pp. 25 ss.

${ }^{24}$ A.d'Ors, Constitutio Antoniniana (P. Giess. 40,I): Contribución al estudio de su valor y significado para la Historia del Derecho Romano. Tesis Doctoral (Universidad de Madrid 1941); cfr. Giménez-Candela, In memoriam, Alvaro d'Ors, en SZ.122 (2005) p. 450 y 454 s.; id., Alvaro d'Ors (1915-2004), en REHJ. 27 (2005) p. 642 y 647s.

${ }_{25}$ A. d'ORs, Sobre el no-estatismo de Roma, Ensayos de teoría política (Pamplona 1979) 58s.; DesIDERI, «La romanizzazione dell'Impero», en Storia di Roma 2.II (Torino 1991) pp. 624 ss.

${ }^{26}$ H. J. Wolff, Polis und Civitas, en SZ. 95 (1978) pp. 1 ss.

${ }^{27}$ Vid. Con lit. actualizada, Giménez-Candela, Civitas civium, en Polis. Studi interdisciplinari sul mondo antico II (2006/2) p. 196s.; SANTANGELO, «Confini di città e confini di pagi nell'Italia romana. Il problema del 'dualismo limitaneo'», en Statuti municipali (cit.) pp. 615 ss.
} 
existente y en modo alguno desarraigada por la medida imperial ${ }^{28}$. De ello dan prueba los numerosos documentos procedentes de Egipto, como han puesto de relieve los estudios de Taubenschlag ${ }^{29}$; Arangio-Ruiz ${ }^{30}$, H.J. Wolf ${ }^{31}$, entre otros. Es cierto que Egipto debe ser objeto de una consideración especial, pero situaciones análogas de coexistencia de derecho imperial y costumbres locales se presentan también en otros ámbitos geográficos del Imperio, como en Arabia (así lo ponen de relieve las fórmulas de Babatha ${ }^{32}$ ), en Campania (el edicto de Augusto sobre el acueducto Venafrano ${ }^{33}$ ), o en Hispania como parecen indicar las fórmulas documentadas en el bronce de Contrebia, sobre un pleito de aguas, sometido a un arbiter, entre dos comunidades indígenas del valle del Ebro $^{34}$. Es claro que dicha resistencia fue mayor, donde la costumbre indígena gozaba de mayor arraigo.

En el campo de la administración provincial, ha prevalecido durante largo tiempo la visión mommseniana ${ }^{35}$, tributaria también de la ideología liberal del pasado siglo, tendente a considerar los municipios como un módulo organizativo de las relaciones entre Estado y comunidad, que, bajo perfiles homogéneos y fungibles, sirvió como instrumento para la repetición en provincias de las estructuras romano-itálicas, lo que se lograba a través precisamente de las leyes municipales que dotaban de un estatuto de reconocimiento de autonomía a una comunidad ciudadana ${ }^{36}$. Sin embargo, dicha concepción

\footnotetext{
${ }^{28}$ Vid. supra n. 1.

29 Taubenschlag, The Law of Greco-Roman Egypt in the Light of the Papyri. 332 B.C.-640 A.D. (Warszawa 1955); IDEM, «Geschichte der Rezeption des römischen Privatrechts in Aegypten», en St. Bonfante I (Pavia 1929).

30 Arangio-Ruiz, Persone e Famiglia nel Diritto dei Papiri (Milano 1930).

31 H. J. Wolf, Das Recht der grieschichen Papyri Aegyptens II (München 1978).

${ }^{32}$ NÖRR, «Römisches Zivilprozessrecht nach Max Kaser: Prozessrecht und Prozesspraxis in der Provinz Arabia», en SZ 115 (1998) pp. 80 ss. (=Historiae Iuris Antiqui III [Goldbach 2003] pp. 2199 ss.).
}

${ }^{33}$ Edictum Augusti de aqueductu Venafrano, CIL.X,4842 (=ILS, 5742). Vid. DE RoBERTIS, L'espropiazione per pubblica utilità in Diritto Romano (1936) pp. 113 ss.; A. D'ORS, EJER. (=Epigrafía Jurídica de la España Romana [Madrid 1953] pp. 229 s.; RoDRíGUEZ NEILA, "Aqua publica y política municipal romana», en Gerion 6 (1988) pp. 226 s.; GEIßLER, Die öffentliche Wasserversorgung im römischen Recht (Berlin 1998).

${ }^{34}$ Cfr. FAtÁs, El nuevo epígrafe latino de Botorrita o «Bronce de Contrebia» (Zaragoza 1980); A. d'Ors, «Las fórmulas procesales del Bronce de Contrebia», en AHDE 50 (1980) p. 1 ss.; BIRKSRODGER-RICHARDSON, «Further Aspects of the Tabula Contrebiensis», en JRS 74 (1984).

35 Mommsen, Römisches Staatsrecht III.1, «Das municipalrecht im Verhältnis zum Städte» (Leipzig 1887) pp. 773 ss.; FERRARI, «La découverte des lois municipales (1755-1903). Une enquête historiographique», en Statuti municipali (cit.) pp. 104 s.

${ }^{36}$ LAMBERTI, «Tabulae Irnitanae» (cit.), p. 256: «le leges datae erano concepite como elemento fondamentale del processo di romanizzazione delle province «; A. d'ORs, Sobre legislación municipal (rec. amplia a Lamberti, «Tabulae Irnitanae» [cit.]), Labeo 40 (1994) pp. 100 s. 
ha entrado en crisis a medida que se han realizado estudios sectoriales por épocas históricas ${ }^{37}$, o por ámbitos geográficos ${ }^{38}$.

No parece haber rastros de semejante lucha entre poder central y autonomía municipal. La proliferación de municipios de ciudadanos y, más aún, de latinos se inscribe dentro de un fenómeno previsto, y absolutamente frecuente entre los pueblos de la Antigüedad, cuya tradición habría seguido Roma; a saber, la posibilidad de coexistencia bajo un mismo poder de derechos, formas de administración y estatutos personales distintos ${ }^{39}$. Las leyes municipales españolas, que responden a un mismo modelo común, y son fruto de la extensión en época flavia de un modelo de ley municipal de época augúste ${ }^{40}$, no tienen comparación con las de ningún otro lugar del Imperio, simplemente porque no tuvo, dicha ley municipal, una extensión general a provincias, sino que más bien lo que abundaron -y sobre todo en Orientefueron estatutos especiales que respetaron la arraigada tradición de autonomía de las $\pi \circ \lambda \iota \sigma^{41}$. No hay que olvidar que Hispania, frente a otras provincias del Imperio, presenta la singularidad de haber recibido el ius latii por concesión de Vespasiano en el 73-74d.C.42, lo que junto con la consiguiente proliferación de ciudadanos, acontecida en pocas generaciones, habría hecho

\footnotetext{
37 Grelle, L'Autonomia cittadina fra Traiano e Adriano (Napoli 1972).

38 AlFöldy, Römische Städtewesen auf der neukastilischen Hochebene (Heidelberg 1987) 22 ss.; GALSTERER, Die 'Freiheit' der Städte im Westen des Reiches, Mediterraneo Antico 2 (1999) pp. 545 ss
}

39 AlFöldy, Römische Städtewesen 26s., señala con razón que cada zona del Imperio debe considerarse con criterios específicos; así, lo que en el norte de Africa aparece como comunidades dependientes, se refieren en los territorios danubianos a los municipios o colonias, y en las provincias galo-germánicas las mismas instituciones se presentan como formas rígidamente estatalizadas.

${ }^{40}$ Vid. sumariamente, A. d'Ors, «Nuevos datos de la ley Irnitana sobre jurisdicción municipal», en SDHI 49 (1983) pp. 18 ss.; SIMSHÄUSER, «La jurisdiction municipale à la lumière de la lex Irnitana», en $R H 67$ (1989) pp. 621 ss.; IDEM, «Stadtrömisches Verfahrensrecht im Spiegel der lex Irnitana», en SZ 109 (1992) pp. 163 ss.; RoDGER, «The lex Irnitana and procedure in the civil Courts», en JRS 81 (1991) pp. 74 ss.; LAMBERTI, «Tabulae Irnitanae», (cit.) pp. 139 ss.; IDEM, «La "maggiore etá" della lex Irnitana. Un bilancio di diciotto anni di studi», Minima Ep. et Pap. $3 / 4$ (2000) pp. 248 ss. (con una relación de la literatura pertinente); J. G. WoLF, «Iurisdictio Irnitana», en SDHI 66 (2000) pp. 29 ss. Una actitud abierta a esta hipótesis, ahora, MANTOVANI, «Il iudicium pecuniae communis. Per l'interpretazione dei capitoli 67-71 della lex Irnitana», Gli Statuti Municipali (cit.) 11. 1 p. 261. La literatura sobre la polémica que sigue suscitando la hipótesis d'orsiana (vid. p. e.: A. d'Ors, «La nueva copia Innitana de la lex Flavia municipalis», AHDE 52 [1983] pp. 8 ss.; 49 [1980] pp. 20 ss.; La ley Flavia municipal. Texto y comentario [Roma 1986] pp. 13 ss.), puede seguirse en: ToMLIN, «The Flavian Municipal Law: one or two more copies», ZPE 141 (2002) pp. 281 ss.; BERTOLDI, Lex Iulia iudiciorum privatorum (Torino 2003); una actitud escéptica, adhiriéndose a las reservas expresadas en su momento, entre otros, por Luraschi (Sulla lex Irnitana, SDHI. 55 [1989] p. 353 ss.), parece mantener PARICIO, «La lex Aebutia, la lex Iulia de iudiciis privatis y la supuesta lex Iulia municipalis», Labeo 49 (2003) pp. 135 ss.

${ }^{41}$ Galsterer, «Die römischen Stadtgesetze», en Statuti municipali (cit.) pp. 31 ss. GABba, «Le oportunità del decentramento. Municipalizzacione del Italia e continuità dei ceti dirigenti locali», en Statuti municipali (cit.) pp. $576 \mathrm{~s}$.

${ }^{42}$ Vid. MentXaka, El senado municipal en la Bética Hispana a la luz de la lex Irnitana (Vitoria 1993) pp. 39 ss.; M. ZIMMERMANN, «Galba und die Verleihung des ius Latii an "ganz Spanien" durch Vespasian, Fremde Zeiten». Festschrift für Jürgen Borchhardt zum sechzigsten Geburstag am 25. Februar 1996, II (Wien 1996) pp. 243 ss. 
de la municipalización casi un acto protocolario que hasta lugares tan insignificantes como Irni podían permitirse reclamar.

Lo que resulta difícil de determinar es, entonces, qué derecho se aplicó. Es decir, si fuera de Roma y de Italia el Derecho Romano que se aplicó es el que nos dan a conocer los textos de los juristas o, por el contrario, la praxis del derecho obedecería a los conocimientos de los jueces, que eran los que deberían aplicarlo ${ }^{43}$, y coexistirían entonces, con toda naturalidad, los derechos propios de los municipes junto con el ordenamiento romano-itálico ${ }^{44}$. Me resulta difícil pensar que una ley municipal pudiera tener el efecto globalizador (diríamos hoy) de borrar de provincias los derechos locales. Y desciendo sólo a un detalle: los gobernadores provinciales (representantes del poder central) entre cuyas competencias figuraba la aplicación del derecho, eran asesorados por un consilium (un comité) de expertos, conocedores de los usos locales, que no cambiaría cada dos años, sin que constituiría un cuerpo estable cuya misión sería la transmisión al gobernador de ese acervo de prácticas $^{45}$, que también los gobernadores anteriores habrían respetado y aplicado, junto con el derecho romano-itálico.

Cierto es que expresiones como Orbis Romanus, o Patria communis (que merece una reflexión aparte), tienen un claro sentido totalizador, lo mismo que el término romanización, para hacer referencia al complejo proceso de asimilación de las formas culturales romanas, por parte de los nuevos territorios conquistados ${ }^{46}$. Pero los textos en que estas expresiones aparecen, $o$ en que dicho proceso de asimilación cultural figura como ejemplificador, deben ser sometidos a crítica nuevamente ${ }^{47}$.

\footnotetext{
${ }^{43}$ Volterra, Diritti locali (cit.) p. 62 i.f. y s.; CAMODECA, «La prassi giuridica municipale. Il problema dell'effetività del Diritto Romano», en Statuti municipali (cit.) pp. 515 ss., esp. 522 y 546.

${ }^{44}$ Humbert, «Municeps et municipium», en Statuti municipali (cit.) pp. 26 ss.

${ }^{45}$ GiméNEZ-CANDELA, «Bemerkungen über Freilassungen in consilio», en SZ 126 (1996) pp. 70 ss.; IDEM, «La práctica de las manumisiones en suelo provincial», en Labeo 48 (2002) pp. 399s.

${ }^{46}$ Desideri, La romanizzazione dell 'Impero, Storia di Roma II. 2. I principi e il mondo (Torino 1991) $580 \mathrm{ss}$

${ }^{47}$ El tópico de Roma como communis patria, tan usado como justificación de un sistema de poder que favoreció la expansión de un orden jurídico al que cualquier ciudadano romano podía acogerse, puede verse como uno de esos ejemplos de ficción jurídica con inmediatas secuelas prácticas y procede, muy probablemente, de A. Aristides, $\varepsilon \iota \sigma$ Pounv 61, si bien en Tácito (Tac. Ann. 3,40) y Plinio (Plin. Pan. 37,5) ya se había sugerido con un trasfondo político. KLEIN, Die Romrede des Aelius Aristides. Einführung (Darmstadt 1981); A. ARISTIDES, Übersetzung und Erläuterung (Darmstadt 1983); BEHR, «Studies on the Biography of Aelius Aristides», ANRW II, 34,2 (1994) p. 1140 ss.; LIBRALE, «L'Eis Basilea dello pseudo Aristide e l'ideologia traianea», ANRW II, 34,2 p. 1271 ss.; MoresChINI, «Aelio Aristide tra Retorica e Filosofia», ANRW II, 34,2 1234 ss.; STERTZ, «Aelius Aristides Political Ideas», ANRW II, 34,2 pp. 1248 ss. La Jurisprudencia romana utiliza la expresion communis patria sólo en tres textos, uno de los cuales se debe a Calístrato (D.48,22,18 [19] pr.), y dos a Modestino (D.27,1,6,11; 50,1,33). El segundo texto, procedente del libro singularis de manumissionibus de Modestino, fue colocado por los Compiladores bajo la rúbrica ad municipalem et de incolis, por razones que no son fáciles de afirmar con seguridad (Lenel, Palingenesia II, 721, lo relega al final de su reconstrucción del mencionado libro de manumissionibus, quizá por no adivinar qué relación podía tener con los restantes fragmentos). Sobre el tema, una selección de la literatura más relevante debe incluir: NöRR, «Origo. Studien zur
} 
La cuestión es en qué medida se salvaguardó la libertas de la ciudad, mediatizada por los filtros reguladores de la administración imperial, o dicho en otros términos, cómo se armonizaron los principios de libertad y autonomía con las necesidades de crecimiento y expansión de Roma por el Mediterráneo. La Urbs fue el núcleo central de toda la organización política romana, de ahí la importancia de las ciudades - a pesar del indudable relieve de las provincias-, para la construcción del Imperio Romano ${ }^{48}$. Esta política tuvo una inmediata aceptación y éxito en Oriente, donde la tradición histórica de la polis fue escrupulósamente respetada, pero también en Occidente encontró una indudable acogida.

Roma, en los inicios del Imperio se encontró con la tarea de dominar áreas extensísimas de terreno, para cuyo control y organización contaba con un número exiguo de funcionarios. La administración periférica romana, se identificaba con los gobernadores provinciales y con el estrecho círculo de sus inmediatos colaboradores que no sobrepasarían el número quizá de $200^{49}$, en todas las provincias en época augústea, en un territorio que podría contar con cincuenta/sesenta millones de habitantes de los que sólo cuatro/cinco millones eran ciudadanos romanos ${ }^{50}$. Los cuadros de esta administración, procedían de las grandes familias romano-itálicas, a las que correspondió en principio la tarea rectora en las provincias. Este hecho determinó, sin duda, que muchas otras competencias, por imposición fáctica, se fueran delegando en manos de los habitantes de los asentamientos urbanos periféricos, para lo que fue preciso ir creando estructuras y redes de poder estables. La imagen de la Urbs, repetida en las demás ciudades del Imperio, hacía que, a los ojos de los romanos, aparecieran las ciudades como instrumentos de poder, espejos de la patria común, repetidos inexorablemente en cualquier punto del Imperio, como puentes tendidos entre las lejanas realidades locales y el poder central ${ }^{51}$.

El marco de vida ciudadana, ciertamente sugestivo, es válido, por lo de-

Orts-, Stadt- und Reichszugehörigkeit in der Antike», publicado inicialmente como artículo de la $R E$, ahora en Historiae iuris antiqui I p. 141 ss.; Imperium und Polis (München 1969, 2a ed.) pp. 101 ss.; Sherwin-White, Roman Citizenship (Oxford 1973) 426 ss.; PAVIS D'EsCuRAC, "Origo et residence dans le monde du commerce sous le Haut-Empire», Ktema (13) 1988 pp. 57 ss.; ZAHRNT, Identitätsvorstellungen in den östlichen Provinzen am Beispiel der Romrede des Aelius Aristides, Zur Beschreibung eines Bewußtseins (Köln 1995, ed. H.v. Hesberg) pp. 133 ss.; ThомAs, «Origine et commune patrie». Étude de droit public Romain, 89 av.J-C.-212 ap. J.-C. (Paris 1996); rec. de Giménez-Candela, SZ 115 (1998) pp. 523 ss

${ }^{48}$ Eck, Provinz-Ihre Definition unter politisch-administrativen Aspekt, Was ist eigentlich Provinz? (cit) pp. 16 ss.; HAENSCH, “Capita provinciarum”. Statthaltersitze und Provinzialverwaltung in der römischen Kaiserzeit (Mainz 1997).

${ }^{49} \mathrm{Cfr}$. NICOLET, Rome et la conquête du monde Méditerranéen I. Les structures de l'Italie romaine (Paris 1994) pp. 429 ss.

${ }^{50}$ NICOLET, Rome et la conquête du monde Méditerranéen I, pp. 79 ss.; esp. 88s.; KREMER, «Il censo nelle colonie latine prima della guerra sociale», en Statuti municipali (cit.) p. 628 ss.

${ }^{51}$ Vid. supra 1.47. 
más, hasta el S. I d.C.. Un siglo más tarde tenemos un testimonio de gran interés para observar los posibles cambios que en este cuadro se habían introducido, se trata de la oratio Hadriani de Italicensibus ${ }^{52}$, dirigida por Adriano al Senado en una fecha situada entre el 118 al 121 d.C. Formalmente, este discurso adrianeo tomó ocasión de la petición de los municipes de Itálica, sus propios conciudadanos, que deseaban que la gracia imperial les concediese convertirse en colonia, una forma de promoción a una categoría que seguía considerándose superior a la de municipio ${ }^{53}$. La petición de los italicenses, se insertaba dentro de una corriente de la que ya había precedentes en época de Trajano, que concedió dicho cambio constitucional a Hadrumentum y Lepcis Magna. Lo que muy probablemente perseguían los italicenses, al solicitar el cambio constitucional de municipio a colonia era una mayor vinculación con el emperador, que por el hecho de la nueva fundación colonial asumía nuevas obligaciones respecto a la colonia y, probablemente, la exención de las tasas y gravámenes municipales que habían soportado hasta el momento.

En la referencia que Aulo Gelio nos ofrece de la oratio Hadriani, se hace constar el asombro del emperador por la petición de sus conciudadanos ${ }^{54}$, pues los municipios gozaban de una mayor autonomía basada en poder regirse por sus propias costumbres y leyes indígenas (suis moribus legibusque uti possunt $)^{55}$, lo que contrastaba con la condición colonial organizada con base en los iura del Populus Romanus ${ }^{56}$. Gelio, añade que a Adriano le había pare-

52 Gell. 16,13,1 ss.; vid. Talamanca, «Aulo Gellio ed i 'municipes'. Per una esegesi di Noctes Atticae 16,13», Gli Statuti Municipali (cit.) pp. 445 ss.

${ }^{53}$ Gell. 16,13,3: Sic adeo et municipia quid et quo iure sint quantumque a colonia differant, ignoramus existimamusque meliore condicione e sse colonias quam municipio (=no sabemos en realidad qué es un municipio y en qué se diferencia respecto al derecho de una colonia, pero consideramos que las colonias tienen una categoría superior a la de los municipios). Este aura de prestigio aún se acrecentaba más si el Emperador concedía a una colonia el ius Italicum, como ocurrió en Hispania en los casos de Accis, Valentia, Lisibosa, Pax Iulia y Emerita Augusta; Septimio Severo lo otorgó a las tres ciudades africanas de Lepcis Magna — de donde él era oriundo-, Cartago y Utica; en la Galia gozaron de esta condición Lyon y Antipolis, y Apamea en Bitinia; lo que, en último término, vino a hacer de colonia un título honorífico totalmente ajeno al sentido originario de la palabra. Cfr. sobre ius italicum, Mazzarino, Ius italicum e storiografia moderna, I diritti locali nelle province romane (cit.) p. 357 ss. ; y con especial referencia a Hispania, A. d'ORs, La condición jurídica del suelo en las provincias de Hispania, ibidem, p. 256 ss.

${ }^{54}$ Gell. 16,13,4: De cuius opinationis tam promiscae erroribus divus Hadrianus in oratione, quam de Italicensibus, unde ipse ortus fuit, in senatu habuit, peritissime disseruit mirarique se ostendit, quod et ipsi Italicenses et quaedam alia municipia antiqua, in quibus Uticenses nominat, cum suis moribus legibusque uti possent, in ius coloniarum mutari gestiverint (=el divino Adriano en su discurso ante el Senado se hizo eco del error, frecuente, en que incurrieron los italicenses, habitantes de Itálica — de donde él mismo era oriundo-, y otros antiguos municipios, entre los que mencionó a Utica, que pudiendo regirse por sus propias leyes y costumbres, solicitaron transformarse en colonias) .

55 Gell. 16,13,6: Municipes ergo sunt cives Romani ex municipiis legibus suis et suo iure utentes, muneris tantum cum populo Romano honorari participes, a quo munere capessendo appellati videntur, nullis aliis nece ssitatibus neque ulla populi Romano lege adstricti, nisi in quam populus eorum fundus factus est...(=los munícipes son pues ciudadanos romanos que se rigen por sus propias leyes municipales y su derecho propio y gozan de la prerrogativa de contribuir a las cargas municipales, a las que están obligados, sin que por ello les obliguen otras leyes propias del Pueblo Romano, salvo las que expresamente acepten...)

56 Gell. 16,13,8: Sed coloniarum alia necessitudo est; non enim veniunt extrinsecus in civitatem nec suis radicibus nituntur, sed ex civitate quasi propagatae sunt et iura institutaque omnia populi Roma- 
cido más sensata la petición de los habitantes de Praeneste, que habían solicitado de Tiberio pasar de colonia a municipio, beneficio que habían obtenido en agradecimiento del emperador por haber sanado allí de una grave enfermedad ${ }^{57}$. La razón de esta petición de los italicenses estriba, según Gelio, en la confusión y el olvido de las categorías de colonia y municipio ${ }^{58}$, lo que indirectamente viene a confirmar el proceso de uniformización entre las ciudades que en el S.II d.C. era ya un hecho. De tal suerte que las reglas constitucionales, basadas en un prudente equilibrio entre autonomía y poder central —que habían servido a Roma para asentar su hegemonía en la época de las conquistas-, se habían ido desvaneciendo para ser paulatinamente sustituidas por una mayor intervención del poder central en la vida de las comunidades. La libertas republicana, que partía del respeto y conservación de las diferencias indígenas, venía así a ser sustituida por una libertad, basada en una nivelación de la diversidad, que hiciera preferible la semejanza a la Urbs que la variedad indígena. Un siglo más tarde, el edicto uniformista de Caracalla no hará sino reconocer formalmente lo que en la práctica era ya un hecho consumado. La decadencia del Imperio fue precedida de una decadencia de las ciudades, como no ha dejado de reconocerse ${ }^{59}$.

Los entes autonómicos han potenciado en España el ejercicio de las libertades ciudadanas, se trata ahora de avanzar un tramo más en ese devenir. Si aquéllos han servido como vehículos imprescindibles para potenciar el tránsito a formas constitucionales de carácter democrático, no debe coartarse, a mi juicio su desarrollo y evolución hacia formas más perfeccionadas que posibiliten que las ciudades se conviertan en ese lugar donde permanecer, al que Konstantinos Kavafis aludía en unos versos que me vienen ahora a la memoria ${ }^{60}:$ «No hallarás otra tierra ni otra mar./La ciudad irá siempre dentro de tí. Volverás/ a las mismas calles. Y en los mismos suburbios te llegará la vejez;/ en la misma casa encanecerás./ Pues la ciudad siempre es la misma. Otra no busques — no la hay_,/ ni caminos ni barco para tí./

ni, non sui arbitrii, habent (=la vinculación de los colonos sin embargo es distinta, pues no acceden a la ciudadanía desde afuera ni tomando sus raíces como punto de apoyo, sino que constituyen prácticamente una extensión de la ciudadanía romana y adoptan el derecho y las instituciones del Pueblo Romano no por propia elección).

57 Gell. 16,13,5: Praenestinos autem refert maximo opere a Tiberio imperatore petisse orasseque, ut ex colonia in municipii statum redigerentur, idque illis Tiberium pro ferenda gratia tribui sse, quod in eorum finibus sub ipso oppido ex capitali morbo revaluisset (=los Prenestinos, se dice que, solicitaron formalmente del emperador Tiberio que les concediera convertirse de colonia en municipio, lo que graciosamente les otorgó Tiberio, dado que en la mencionada ciudad sanó de una grave enfermedad).

${ }^{58}$ Gell. 16,13,9: Quae tamen condicio, cum sit magis obnoxia et minus libera, potior tamen et praestabilior existimatur propter amplitudinem maiestatemque populi Romani, cuius istae coloniae quasi effigies parvae simulacraque esse quaedam videntur, et simul quia obscura oblitterataque sunt municipiorum iura, quibus uti iam per innotitiam non queunt (=Tal categoría [colonial] si bien conlleva más dependencia y menos libertad, se considera en cambio más distinguida [que la municipal] debido al superior prestigio y dignidad del Pueblo Romano, al que estas colonias se asemejan como imágenes reducidas, y debido también a la oscuridad y olvido en que han caído los derechos de los municipios, que por ignorancia han dejado de practicarse) .

59 W. E. Heitland, Repetita (Cambridge 1930); A. d'ORS, EJER p. 142.

${ }^{60}$ K. Kavafis, «Polis», Poesía completa. 1863-1993 (Madrid 2004). 